\title{
VIVÊNCIA DE DESBLOQUEIO NA CONSTRUÇÃO DO PAPEL DE SARAH - UNLOCKING
}

\section{EXPERIENCE ON SARAH PAPER CONSTRUCTION}

\author{
Carmen Lorena Jamarino Andrade Parreira \\ lorenajamarino@bol.com.br \\ UFOP
}

\section{Resumo:}

O objetivo deste artigo é investigar a integração da linguagem de Harold Pinter com a noção de Alvo de Declan Donnellan. Para isso, utilizaremos exemplos da montagem da peça Amante ${ }^{1}$, de Harold Pinter. Nossa intenção é examinar como o ator pode construir um papel pinteriano sem se bloquear pela característica de dissimulação da linguagem do dramaturgo. Como consegue trabalhar com a inversão de uma linguagem de mentiras em uma linguagem com aparência de verdade sem que esta seja comprovada para o espectador o que é verdade ou apenas dissimulação. Nossas experiências da sala de ensaio comprovaram que o instrumento Alvo, forjado pelo diretor britânico Declan Donnellan, se apresentou como altamente eficaz na solução dos problemas.

Palavras-chave: Linguagem Pinteriana, Alvo Donnelliano, Construção do Papel, Trabalho de Ator.

\section{Abstract:}

This text seeks to integrate Pinter's language with Donnellan's target by using examples from stage-rehearsals in the production of Pinter's play The Lover. Our intention is to investigate a way in which the actor can work on a Pinter's character without being blocked by the author's language which conveys evil intentions and vile meanings. Working on a role, in Pinter's plays, is to learn how to replace the right angle by an obtuse one or the adjacent one. Our experiments reveal Donnellan's target a very effective device to solve the problem and, consequently, to help the actor.

Keywords: Pinteresque Language, Donellan's Target, Work on a Role, Actor's Work.

Durante a minha trajetória no Curso de Graduação em Teatro da Escola de Belas Artes da Universidade Federal de Minas Gerais, pude vivenciar muitas experiências nas diversas disciplinas oferecidas. Paralelamente, trabalhava como atriz na cidade de Belo Horizonte. Essas duas vidas foram sendo mescladas e comparadas, uma vez que revelavam aspectos controversos no que diz respeito ao fazer teatral.

\footnotetext{
${ }^{1}$ Dramaturgia: Harold Pinter. Tradução: Luiz Otavio Carvalho. Atuação: Lorena Jamarino e Gustavo Andrade. Direção: Luiz Otavio Carvalho. Assessoria corporal: Lúcio Honorato.
} 
Uma das experiências com a qual mais me identifiquei foi o trabalho de pesquisa teórico e prático sobre atuação cênica desenvolvido no Estúdio Fisções. Este Estúdio é um Laboratório que tem por princípio treinar atores em atuação cênica a partir da utilização da Ação Física segundo os princípios de Stanislavski (1863-1938). O professor e coordenador do Estúdio, Luiz Otavio Carvalho, desenvolvia uma série de exercícios na construção de partituras de Ação Física, sempre circunstanciadas em um texto dramático de dramaturgos reconhecidos. Nesses exercícios, praticávamos reações ao espaço, à palavra, ao parceiro de cena, aos objetos cênicos e, destacadamente, à conduta de personagens em diferentes contextos. Na maioria das vezes, esses atores, que chegam a participar desses exercícios de treinamento, se demonstram com dificuldades, ou seja, bloqueados. Para isso, o professor utiliza a teoria do Alvo, sistematizada pelo diretor britânico Declan Donnellan (1953- ), como metodologia de facilitação para a prática da Ação Física. Dessa forma, cenas de peças de dramaturgos renomados da literatura dramática são encenadas como exercícios de aplicação prática do treinamento.

Outro fato que me marcou significativamente durante o Curso de Teatro, na UFMG, foi a Disciplina sobre Encenação de Peças do dramaturgo inglês Harold Pinter (1930-2008), ministrada, também, pelo professor Luiz Otavio Carvalho. Pudemos ler, dentre as 29 peças do autor, 17 peças, com tradução do próprio professor, e outras duas, com tradução de outros tradutores, além de quatro sketches de revista, publicados nos Cadernos de Teatro no 120. Ao longo dessas leituras, o professor estudava as características da dramaturgia, das personagens, da linguagem pinteriana por meio de autores renomados da literatura crítica teatral, tais como Martin Esslin, John Russell Taylor, Christopher Innes, entre outros. Paralelamente, fazíamos exercícios práticos de composição cênica onde podíamos experimentar essa linguagem e a construção das personagens no jogo prático cênico pinteriano.

Ao atingir o momento, então, de realizar o meu Trabalho de Conclusão do Curso (TCC) como parte dos requisitos para aquisição do título de Bacharel em Interpretação Teatral, escolhi uma peça de Harold Pinter para encenar. A peça eleita foi Amante (The Lover), escrita em 1962, com a tradução do professor Luiz Otavio Carvalho. Como não poderia deixar de ser, convidei o professor para também dirigir o exercício cênico, pois tinha a intenção, com esse exercício cênico, de apresentar os resultados dessa singela bagagem de conhecimento que adquiri na graduação e 
que foram, destacadamente, parte dos estudos que realizei sob a orientação do referido professor. Digo singela, pois o artista nunca está pronto por completo.

Para a montagem da peça, convidei o ator Gustavo Andrade, também graduado no Curso de Graduação em Teatro EBA/UFMG - Bacharelado em Interpretação Teatral -, para ser meu parceiro de cena. Logo no início do processo, começamos a trabalhar a peça da maneira que costumávamos fazer em outras experiências teatrais. Estudamos o texto e começamos a definir essas personagens por meio das seguintes questões: quem eram, o que faziam e por que faziam o que faziam. Criamos antecedentes sobre a vida dessas personagens. Em seguida, fomos para o espaço com alguns objetos de cena que idealizamos e tentamos atuar essas personagens a partir de nossas anotações. Criamos intenções e sensações para o que fazíamos e falávamos. Tentamos reagir ao máximo sob a influência de nossos apontamentos.

Ao apresentarmos esse primeiro esboço de improvisações para o diretor, este comentou que parecia que estávamos agindo a partir de pressupostos de um relacionamento com padrões de conduta tradicionais. Apontou que estávamos tentando nos comportar como se fôssemos um casal de fato e nossas falas soavam como se nós estivéssemos envolvidos, dramática e psicologicamente, em uma discussão de relacionamento de casal. Entretanto, as palavras que eram ditas, as falas cênicas que eram articuladas, a partir do texto do autor, não condiziam com a situação que tentávamos viver. O texto do autor não conseguia servir como base circunstancial para aquele tipo de atuação cênica. Ao nos vermos nesse primeiro impasse, nos bloqueamos e fomos atacados pelas conhecidas dúvidas: O que fazer? Como fazer? Como falar? Como reagir? Como nos movimentamos? O que devemos sentir?

Eis aqui a matéria do presente estudo. Como construir adequadamente um papel a partir da dramaturgia pinteriana e atuar sem se sentir bloqueada? Para que cheguemos nos exemplos ilustrativos de cena, precisarei tecer algumas reflexões sobre a dramaturgia, linguagem e as personagens de Harold Pinter. Acrescida a essa reflexão, farei alguns esclarecimentos sobre alguns aspectos fundamentais sobre o Alvo, da Teoria do Alvo de Donnellan, pois foi por meio dele que conseguimos ir adiante e nos desbloquearmos. Finalmente, trarei alguns exemplos de nossos ensaios para solidificar todo o nosso raciocínio reflexivo. 


\title{
REFLEXÕES SOBRE O TEATRO DE HAROLD PINTER
}

Ao conhecer e estudar o teatro de Harold Pinter, fiquei instigada porque percebi que em suas peças há sempre um mistério a ser desvendado que, no entanto, sempre ficará em suspenso, pois não se trata de thrillers policiais em que um assassino deve ser encontrado. São, simplesmente, situações cotidianas da vida que, nem sempre e quase em sua totalidade, não sabemos porque as coisas acontecem. Ronald Heyman nos esclarece que:

\begin{abstract}
As peças se tornam thrillers, cheias de mistérios que são estabelecidos sem a menor intenção de serem solucionados e com nenhuma pretensão de que o próprio dramaturgo o fará. Funcionam sobre os espectadores espalhando confusões, se deleitando com isso, tirando proveito da situação, mas nunca solucionando alguma coisa. Dicas são lançadas como se fossem pistas de um mistério, mas a trilha das evidências nunca levam à solução alguma (HAYMAN, 1975, pp. 9,10). ${ }^{2}$
\end{abstract}

As personagens pinterianas, portanto, dentro desse contexto, passam a ter características que refletem essa suspensão. São personagens sem antecedentes, histórico de vida e, consequentemente, sem implicações psicológicas. Personagens que vão se delineando à medida que reagem às situações a elas impostas.

Esslin (1984, p. 46) relata que, certa vez, Pinter comentou o porquê é desnecessário para o espectador saber sobre uma vida pregressa de uma personagem, contando a história de uma situação cotidiana sobre uma briga de rua. Ela acontece diante de nós e ninguém se preocupa em saber quem são as pessoas envolvidas na cena real. Os curiosos querem saber, de fato, é o que está acontecendo naquele momento, naquela situação diante de seus olhos. Depois, chegam os policiais, desfazem a confusão, levando os implicados e ninguém nunca fica sabendo realmente o que aconteceu. Ninguém sabe quem são as pessoas envolvidas na confusão, mas, o que parece importar é o que está acontecendo e o desfecho que se dará naquele momento. Entretanto, nem mesmo isso fica conhecido com certezas e detalhes. É isso que acontece com suas personagens. "Pinter não é um dramaturgo naturalista. Esse é o paradoxo de sua personalidade artística. 0 diálogo e as personagens são reais, mas o efeito global é de mistério, de incerteza, de ambiguidade poética" (ESSLIN, 1984, p.41).

\footnotetext{
${ }^{2}$ A partir dessa citação, todas as traduções de Hayman, Esslin (1984) e Pinter foram realizadas por Luiz Otavio Carvalho.
} 
Segundo Pinter, o importante é a situação vivenciada por suas personagens e suas reações diante do ocorrido, não quem são e nem como pensam e sentem. Em relação a esse modo de ver, Hayman transcreve a própria fala de Pinter em que o autor afirma que:

\begin{abstract}
O desejo da verificação é compreensível, mas não pode sempre ser satisfeito. Não há distinções claras entre o real e o irreal, nem entre o que é verdade e o que é falso. Uma coisa não é necessariamente verdadeira ou falsa; pode ser tanto verdadeira quanto falsa. Considero incorreto o pressuposto de que a verificação do que aconteceu ou está acontecendo apresenta poucos problemas. Um personagem que no palco não pode apresentar qualquer argumento convincente ou informação a respeito de sua experiência prévia, seu comportamento presente ou suas aspirações, ou que é incapaz de fornecer uma análise panorâmica de seus motivos, é tão legítimo e tão merecedor de atenção quanto outro que, de forma alarmante, é capaz de todas essas coisas. Quanto mais aguda a experiência, tão menos passível de expressão intelectual (PINTER apud HAYMAN, 1975, p. 9).
\end{abstract}

Pinter afirma que um indivíduo, além de não saber quem ele é ao certo, muito menos sabe como reagir previamente em situações do cotidiano. Então, como o ator pode saber sobre uma personagem com tanta exatidão previamente? Por isso, ele explica que não é necessário esse conhecimento prévio sobre a personagem, sobre suas vidas pregressas. O que importa é realmente o que o ator vê através dos olhos da personagem em cena para reagir às situações mais diversas que vivencia no processo do espetáculo. Consequentemente, por meio desse comportamento de ator em jogo no aqui e agora, Pinter intenciona promover sensações de recepção sobre o espectador da mesma ordem. Isso se evidencia em uma entrevista dada a John Sherwood, na B.B.C., em 03 de março de 1960, quando Pinter comentou que:

Algumas vezes, quando me olho no espelho, não sei quem sou. Não encontro explicações para aquele rosto. A pergunta 'Quem sou eu?' está intimamente ligada com a questão da motivação. Se soubéssemos exatamente quem é a personagem, quais são seus antecedentes, seus gostos, sua rapidez de reação, seu vocabulário, seus valores pessoais, poderíamos prever com certa precisão como ela se comportará no futuro ... essa maneira explícita e detalhista utilizada no drama do século vinte é ... enganosa. 0 dramaturgo simula que temos uma grande quantidade de informação a respeito de suas personagens ao se revelarem diante dos espectadores. Na verdade, o que elas fazem, na maioria das vezes, é se adaptarem à própria ideologia do autor. Elas não se constroem enquanto progridem em suas reações, são postas em cena com o seguinte propósito: falar em nome do autor aquilo que ele tem a transmitir.

Em minhas peças, quando se abre a cortina, vocês se deparam com uma situação, uma situação específica, duas pessoas sentadas em um cômodo em uma situação que não havia acontecido anteriormente e que está acontecendo neste exato instante. Não sabem mais nada a respeito delas assim como eu não sei nada a respeito de vocês. O mundo é repleto de surpresas. Uma porta pode se abrir de repente e alguém pode entrar. Adoraríamos saber quem é, adoraríamos saber exatamente o que ela tem em mente e 
porque entra. Entretanto, com que frequência sabemos o que alguém tem em mente ou quem é essa pessoa, o que ela vai fazer, o que faz dela o que ela é e qual é a sua relação com os outros? (ESSLIN, 1984, pp. 42,43).

A peça Amante, de Harold Pinter, a que elegi como material do meu exercício cênico, é constituída de personagens comuns da sociedade de classe média e a situação se desenvolve em ambientes familiares e cotidianos. À primeira vista parece estarmos diante de uma peça realista em que um tema é apresentado e desenvolvido com o propósito de se chegar a alguma conclusão. A partir do momento em que o universo ficcional avança, deparamo-nos com situações com as quais não temos a menor ideia do porquê estão acontecendo o que ocorre. Conseguirmos experimentar sensações prazerosas ou espantosas que vão de encontro com valores convencionais. Começamos a conhecer personagens das quais não temos a menor informação e nem sabemos sobre suas relações, apenas levantamos suposições. Essas personagens vão vivenciando situações diante de nós e se configurando com algumas características a partir do que fazem e do que falam. Prosseguem, jogam, se confrontam e se deleitam. Ao final, ficamos diante de um leque de possibilidades de conclusões a respeito de quem são e do que se passou.

Amante é assim. Há basicamente duas personagens, Sarah e Richard, que ao longo da peça vivenciam um jogo em que, aparentemente, cada um trai o outro com um amante. No meio da peça, o espectador se surpreende em perceber que cada um era o amante do outro, respectivamente. Sarah amante de Richard, Richard amante de Sarah. Há uma passagem da peça em que achamos que ficou esclarecido que ambos eram casados. Entretanto, surgem outros fatos que solapam essa possível confirmação. Há momentos em que, quase verdadeiramente, achamos ter solucionado o quebra-cabeça das relações entre as personagens, mas, alguns instantes depois, não temos tanta certeza se é isso ou aquilo ou uma terceira possibilidade. O final se estabelece como um coelho tirado da cartola que só acentua a pluralidade de conclusões que o espectador pode inferir. Por exemplo, será que a peça não passa de um delírio imaginativo de uma ou da outra personagem; ou elas são casadas e precisam de jogos estimulantes para sobreviverem a rotina do casamento; ou ainda esses jogos em vez de solucionar, desvirtuaram o relacionamento dos dois como casal?

Acaba-se por se concluir que o que o dramaturgo pretende é que vivenciemos a tensão do jogo de "diferenciar a ficção dos fatos" (HAYMAN, 1975, p. 55) e não que saibamos diferenciar, de fato, o que é e, muito menos, que precisemos dar respostas morais ou estabelecidas para a 
questão daquilo que acontece entre as personagens. Esses aspectos dramatúrgicos corroboram a característica da escrita pinteriana. Pinter, nessa peça, assim como na maioria de sua produção literária, não tem a meta de escrever para contar a história das personagens por meio de suas ações e motivações com conclusões estabelecidas. Sua meta, aqui, antes de mais nada, é apresentar experiências vividas que, na maioria das vezes, não aparentam ser sintonizadas com os valores sociais tradicionais e convencionais. Entretanto, a experiência é vivenciada como tudo que experimentamos na vida, naturalmente.

O Teatro de Harold Pinter, por essa e outras características, é classificado como Teatro do Absurdo. Essa característica de não estabelecer uma fábula de tese ou realista, em que acontecimentos são argumentados e defendidos em uma sequência ao longo de uma história, é uma das características do Teatro do Absurdo. Martin Esslin explica que:

\begin{abstract}
Como o Teatro do Absurdo não tem por objetivo transmitir informações ou apresentar problemas ou destinos de personagens que existam fora do mundo interior do autor, como ele não propõe teses e nem debate proposições ideológicas, ele não se preocupa com a representação de acontecimentos, nem com a narração do destino ou das aventuras das personagens, mas apenas com a apresentação da situação básica de um indivíduo. É um teatro de situação, em oposição a um teatro de acontecimentos em sequência, e por isso mesmo usa uma linguagem baseada na conformação de imagens concretas mais do que em argumentos ou falas discursivas. E já que está tentando apresentar uma sensação de existência, não pode investigar e muito menos resolver problemas de conduta ou de moral.
\end{abstract}

A ação de uma peça do Teatro do Absurdo não pretende contar uma história, mas comunicar uma configuração de imagens poéticas (ESSLIN, 1968, pág. 349.)

Todos esses aspectos sobre o Teatro de Harold Pinter me intrigaram e me fizeram investir na minha pesquisa de como construir um papel inserido em tal contexto. Percebi, de imediato, que essa tarefa exigiria de mim um outro lugar de criação cênica, diferente do que eu estava habituada a fazer. A partir disso dei continuidade aos meus estudos e pude ir para a pesquisa prática, respaldada pelas provocações do dramaturgo, no que tange a construção de um papel. Quando, então, experimentei um momento de bloqueio. Precisava lançar mão da Teoria do Alvo, metodologia que havia praticado no Estúdio Fisções.

\title{
ASPECTOS FUNDAMENTAIS SOBRE O ALVO
}

Basicamente, a Teoria do Alvo, do diretor britânico Declan Donnellan, se fundamenta em reflexões e procedimentos para auxiliar atores e atrizes que, por uma razão qualquer, se veem 
bloqueados em seus processos de criação cênica. Para o diretor britânico, o bloqueio é o principal vilão do ator; é aquele que impede o ator de criar e estar verdadeiramente presente em cena. Isso se dá, segundo o autor, por diversas razões, sendo algumas delas o medo, a desatenção e o controle dominador sobre tudo em volta de si. Donnellan argumenta que, para ele, não existe um ator mais talentoso do que o outro, o que existe é um ator menos bloqueado do que o outro.

No início de suas reflexões em seu livro $O$ Ator e o $A / v O^{3}$, Donnellan faz menção a oito perguntas que, de acordo com ele, são muito comuns de serem bloqueadoras para os atores de um modo geral. Como essas perguntas são em número de oito, ele cria a metáfora de que essas perguntas configuram as patas de uma aranha. São elas:

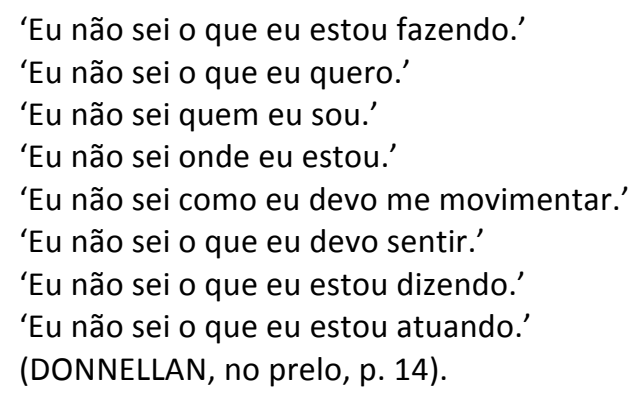

Enquanto o ator estiver sendo assolado por uma delas que seja, ele não consegue progredir cenicamente. Para neutralizar essa paralisia, Donnellan cria um antídoto e o denomina Alvo. O Alvo é aquilo que chamará a atenção do ator, forçando-o a olhar para fora de si mesmo. Isso porque uma das razões que favorecem o aparecimento de uma dessas perguntas é o fato de o ator ficar ensimesmado, isto é, voltado para dentro de si, sem perceber o que acontece em sua volta.

Ao propor a existência do Alvo, como o elemento que atrai a atenção do ator, Donnellan o estabelece como sendo a ferramenta indispensável que deve constantemente atrair a atenção do ator em cena. Não importa se esse alvo é concreto ou imaginário, pessoa ou objeto. O que importa é que ele exista em cena, ou melhor, nas circunstâncias da cena. Dessa forma, o diretor britânico ativa a atenção do ator. Provoca o ator a parar de ficar se fazendo perguntas e, em vez disso, a olhar os Alvos da cena que estão a incitá-lo a tomar atitudes e a reagir.

${ }^{3}$ DONNELLAN, no prelo. 
Para que esse operador conceitual, o Alvo, não ficasse sem referências e, por consequência, ficasse muito abrangente, o autor o balizou com seis regras básicas. São elas: "Sempre existe um Alvo, o Alvo sempre existe exteriormente e a uma distancia dimensionável, o Alvo existe antes que necessitemos dele, o Alvo é sempre específico, o Alvo está sempre em transformação, o Alvo é sempre ativo" (DONNELLAN, no prelo, pp. 17-22).

A partir da criação desse instrumento operacional de desbloqueio, Donnellan, através dos vários capítulos de seu livro, desenvolve reflexões de como ele pode ajudar o ator nos diversos aspectos da construção da cena. Focalizarei minha atenção no que se refere à construção do papel, pois foi quando trabalhava na construção do papel de Sarah, da peça Amante, que meu bloqueio se desencadeou. Devo destacar que o autor britânico não propõe um trabalho de criação do papel, mas sim como o Alvo pode ajudar o ator a trabalhá-lo de maneira fluida, significativa e presente.

Uma das considerações de Donnellan diz respeito à pergunta 'Quem sou eu?' O autor afirma que o ator nunca deve fazer essa pergunta, pois não somos capazes de responder nem para nós mesmos quem somos de maneira plena e esclarecedora, quanto mais em relação a uma personagem. E mesmo que, em relação à personagem, respondêssemos com algumas informações tais como, Sarah é uma mulher de uma condição social equilibrada, Sarah é uma mulher de desejos muito intensos, Sarah é uma mulher de seus trinta e poucos anos, em que essas perguntas ajudaria a mobilizar as reações da atriz em cena. Elas apenas descrevem qualidades, mas não propõem nenhum estímulo ao que fazer em cena. Então ele sugere outra maneira de indagar o assunto que é utilizando duas perguntas em oposição em vez de uma única: quem eu preferiria ser e quem eu teria pavor de ser. Ao responder essas perguntas em conjunto, talvez a atriz pudesse melhor se mobilizar, por exemplo: Sarah gostaria de ter uma vida sexual intensa e teria pavor de se relacionar com um homem que não a satisfaria. Dessa forma, pelo menos, a atriz poderia se mobilizar em lutar por conseguir aquilo que mais a interessa.

Da mesma forma que não é útil ao ator se perguntar 'Quem sou eu?', torna-se, também, perigoso se perguntar 'O que devo sentir?' ao construir um papel. Tudo que o ator tentar fazer para se aproximar daquilo que sua personagem, por ventura, possa estar sentindo, ficará falso, poderá resultar em bombeamento de emoções. Donnellan esclarece que os sentimentos são 
revelados a partir do que fazemos em cena e não do que tentamos sentir. Para isso, precisamos estar atento aos Alvos e reagir sobre eles.

\begin{abstract}
Não podemos expressar emoções. Nunca. Gostando ou não, as emoções, por sua vez, expressam-se por si mesmas em nós. Não conseguimos 'fazer' uma emoção. Não conseguimos 'fabricar' uma emoção. Não conseguimos 'mostrar' uma emoção. Nossas emoções se expressam somente por meio daquilo que fazemos. Por exemplo, para que possamos expressar o ódio por alguém, temos que fazer alguma coisa: digamos, lançar-Ihe um olhar fulminante ou dar-lhe uma bofetada (DONNELLAN, no prelo, p. 108).
\end{abstract}

Tentar construir um papel a partir da identificação do que ele possa sentir em determinado momento é completamente ineficaz e paralisante para o ator. Parafraseando Donnellan (no prelo, p. 109), qualquer tentativa que eu fizer para saber o que Sarah sente, será minha sentença de morte.

Outro aspecto relevante que o diretor britânico nos apresenta é o fato de que tentar se transformar na própria personagem é um trabalho frustrado e em vão. Ele diz:

[...] a missão de se transformar é tão vã quanto a de atingir a perfeição. É importante nocautear, em nossa cabeça, a ideia de 'se transformar'. Não conseguimos mudar nós mesmos. Não conseguimos transformar nós mesmos. Permanecemos o que somos, somente o alvo é que se modifica (DONNELLAN, no prelo, p. 55).

No lugar de tentar se transformar, ele propõe que o ator veja através dos olhos da personagem. O ator, assim, verá alvos que o solicitam a tomar uma atitude, alvos que se transformam e, dessa forma, a personagem também se transforma. Isso se torna um recurso eficaz de desbloqueio do ator, porque possibilita-o a determinar as reações que deve executar em cena. $\mathrm{O}$ ator não pode por ele mesmo mudar a personagem, mas ao ver os alvos e transformá-los com suas reações, ele promove o percurso do papel, contribuindo na criação de características desse papel e das relações cênicas. Donnellan é bastante enfático sobre a questão de que o ator, em cena, não possui o controle das coisas. "Podemos apenas ver a vida que já está esperando para fluir. Nem mesmo conseguimos tentar 'passar' vida. Mas podemos ter como meta não impedir que a vida flua" (DONNELLAN, no prelo, p. 57).

Todos esses aspectos sobre o Alvo e algumas de suas implicações ponderadas por Donnellan no auxílio do ator que está construindo seu papel me fizeram perceber fortes ligações com as características previamente analisadas sobre a personagem pinteriana. Comecei a 
vislumbrar possibilidades de me desbloquear, melhor, de resolver a minha atuação por meio de ver as provocações que as situações da dramaturgia de Pinter me fornecia. Assim pude desenvolver o meu trabalho de atriz com fluência, presença e segurança. Destacarei a seguir, exemplos comentados, como resultado de minhas percepções dessa conjunção Pinter e Donnellan.

\section{EXEMPLOS COMENTADOS NA CONSTRUÇÃO DO PAPEL DE SARAH NA PEÇA AMANTE, DE HAROLD PINTER}

Iniciarei essa seção com a primeira cena da peça. Para isso a transcreverei abaixo:

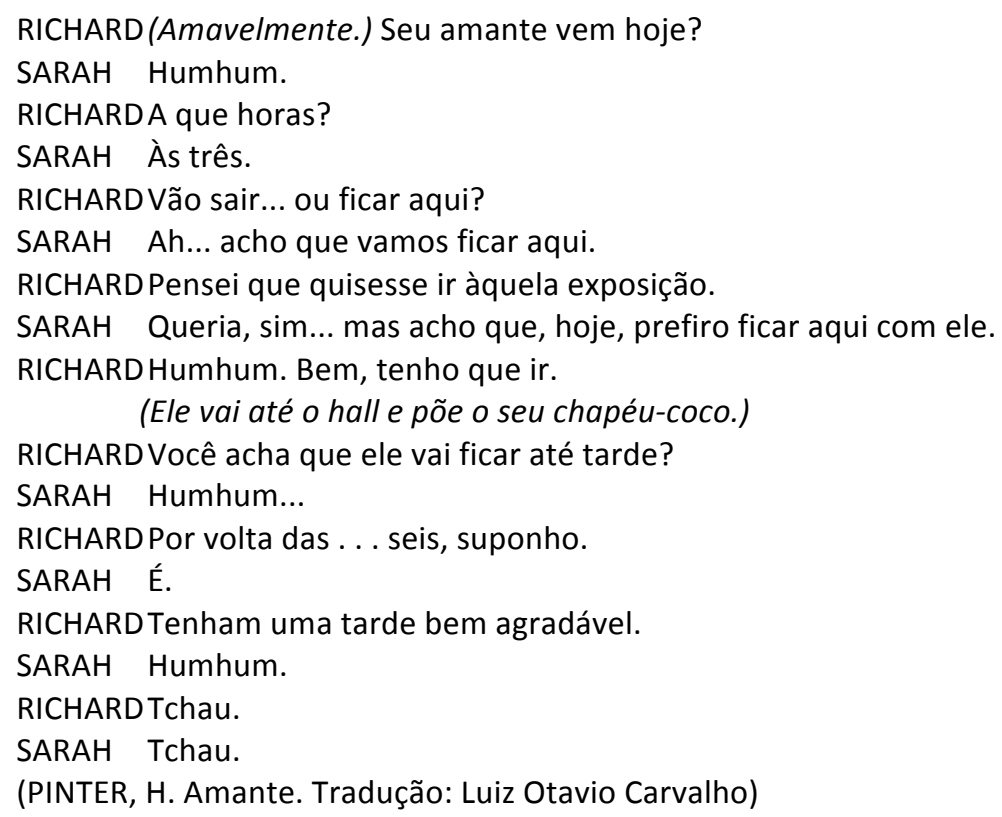

Inicialmente, eu havia considerado que as circunstâncias propostas da cena era a de um casal em que o marido controlador tentava inibir ou conter os arroubos libertinos de sua esposa. Em contrapartida, a esposa sob vigilância tentava esconder seus momentos de prazer fora do casamento. Isso causou um choque paradoxal negativo entre o comportamento de Sarah e o texto proposto pelo dramaturgo. A cena se apresentava dramática e, ao mesmo tempo, completamente inverossímil. Por outro lado, foi difícil não imaginar dessa maneira, uma vez que considerava que ambos eram marido e mulher. Em outras palavras, parti das perigosas perguntas 'Quem é Sarah?' e 'O que Sarah sente diante do marido ao falar do amante?' 
Fomos para jogo da cena. Quando o ator Gustavo me perguntava: "seu amante vem hoje?", eu reagia dizendo de forma constrangida, já que ele reagia de forma opressora ao fazer a pergunta. As reações faladas e, consequentemente, refletindo em reações corporais, pareciam corretas de acordo com a situação constrangedora que propunha a indagação. Porém, sem perceber, não reagíamos de acordo com o verdadeiro texto proposto por Pinter.

O diretor Luiz Otavio Carvalho entra em ação com seu trabalho, e nos mostra as reais circunstancias propostas de que não tínhamos nenhuma informação sobre quem eram aquelas personagens. Além disso, o diálogo se apresentava como uma conversa de sugestões e negociações de ações, em vez de se configurar em atos de recriminar, coibir, esconder e disfarçar. Isso vinha ao encontro das características dramatúrgicas pinterianas estudadas. No entanto, causou-me um bloqueio.

Utilizando-me das reflexões de Donnellan, comecei a vislumbrar saídas. De maneira objetiva, olhei através dos olhos da personagem e percebi que eu estava sendo solicitada a prestar uma informação e não cobrada por atos ilícitos. Assim sendo, minha reação era a de fornecer as informações de maneira mais precisa possível para que tudo acontecesse sem atropelamentos. Utilizei, a partir desse momento, os objetos de cena em sua função mais objetiva. Um livro sobre a poltrona me convidava a folheá-lo, por exemplo. Era, na verdade, uma partitura de uma negociação cotidiana e não de repressão marital. Dessa forma, a comunicação teatral atingia o propósito de não contar uma história, mas a de apresentar uma situação, por mais estranha que pudesse parecer.

Outro exemplo é a cena em que Sarah se encontra com o seu amante Max:

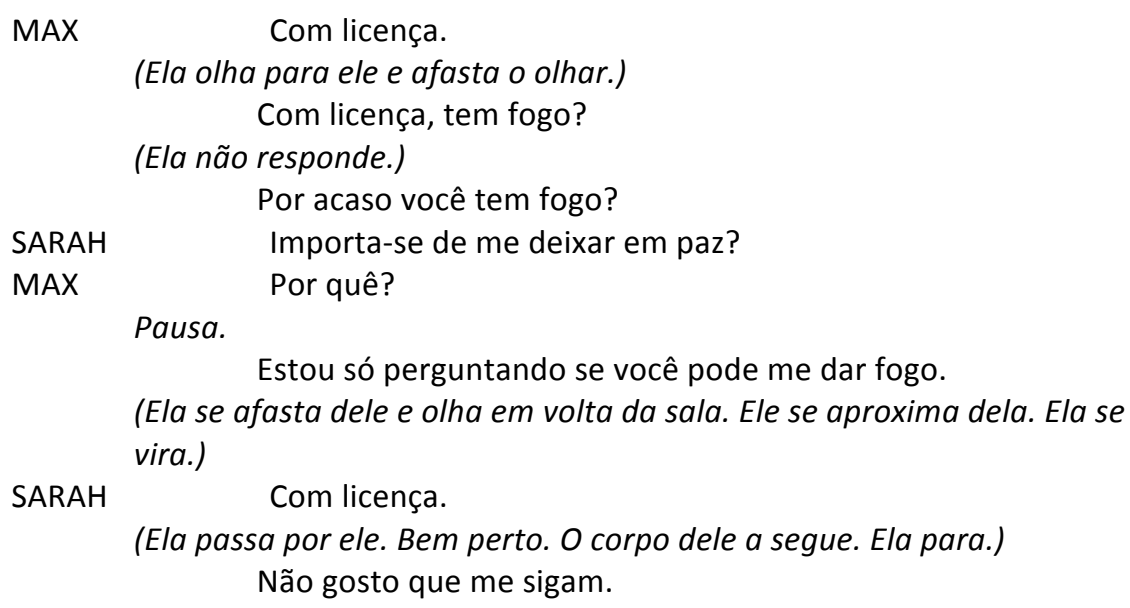




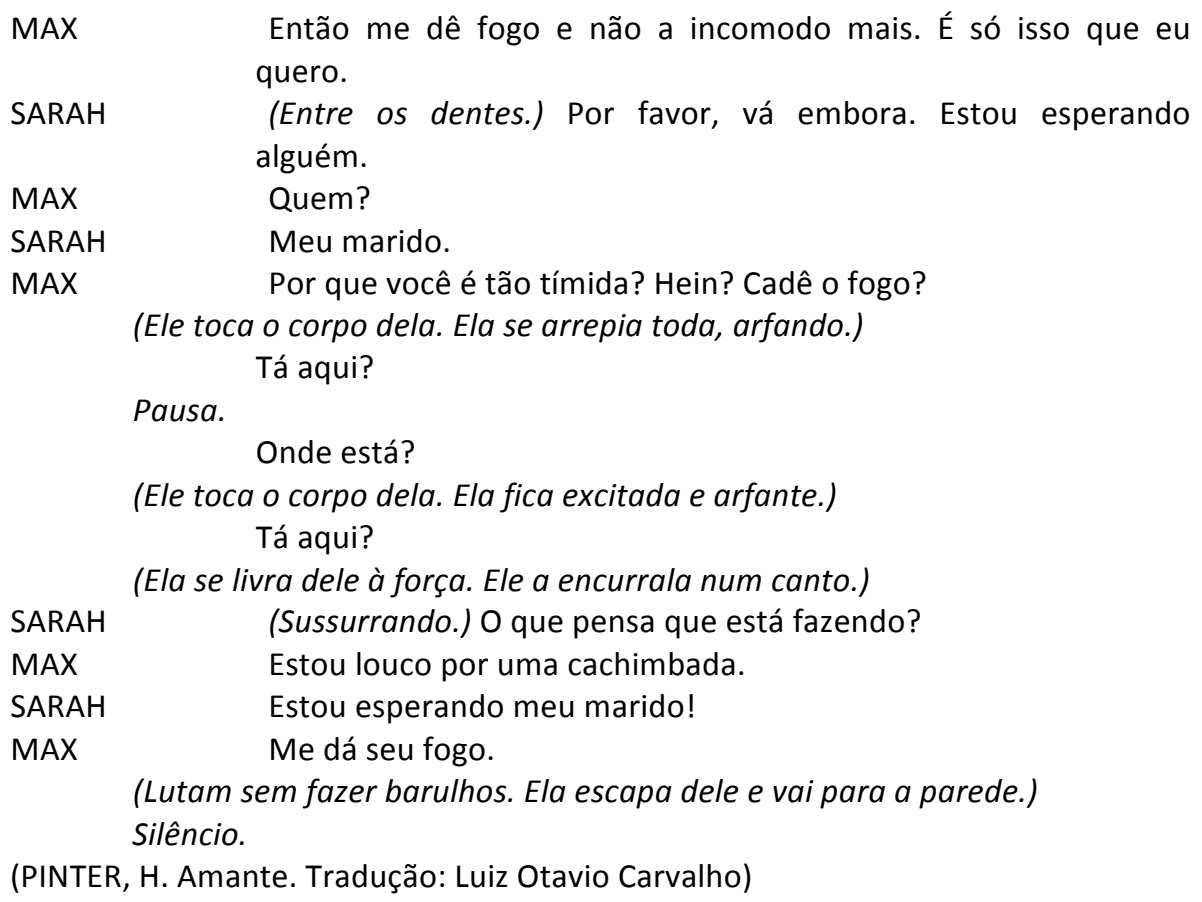

Essa foi uma cena que vimos muitos alvos e utilizamos de todos os verbos idealizados por Pinter e outros necessários a cena, como por exemplo, os verbos atacar, figir, dissimular. Pensando nos verbos, e nas provocações do texto criamos as partituras, a partir dos alvos que a cena nos mostrava. No primeiro momento, quando Max chega, Sarah o aborda, pois ele era seu alvo. Sarah então o ataca para seduzi-lo. No entanto, Max a ignora e foge da sua sedução, indo direto para xicara de café que era seu alvo. Max pega a xícara de café. Porém seu alvo se transforma e Sarah passa a ser o alvo. Max, então, a provoca com sua virilidade, quando enfia seu dedo na xícara, após cair a colher de mexer o café. Sarah, instigada pelo alvo Max, corre para ele e o ataca, em um frenesi de carícias. Max então, passa a ter as carícias de Sarah como alvos e se entrega a ela. Após atingir o gozo, Sarah se afasta, pois agora seu alvo passa a ser o cigarro, no qual ela relaxa após a suposta transa. No entanto, Max ainda tem Sarah como alvo e a aborda. Ele a persegue perguntando se ela tem fogo. Sarah, porém, foge de Max, pedindo pra que ele a deixe em paz. Porém, Max ainda tendo Sarah como alvo a ataca, agarrando-a por trás e perguntado porque ela é tímida. Neste momento, o alvo de Sarah passa a ser o marido que supostamente vai chegar, mas ao mesmo tempo ela deseja Max e o prazer que ele pode the proporcionar. Sarah tenta fugir de todas as formas, entra em combate físico com Max, seu alvo é Max, e fugir dele é sua meta. Max a ataca e a coloca no chão, de forma que ela não consiga sair fácil. Os dois em uma luta dissimulada, se separam, pois Sarah derruba Max e foge e Max fica no chão. 
Na continuidade dessa mesma cena, o dramaturgo Harold Pinter propõe novos alvos instigadores, transformando o jogo dos atores:

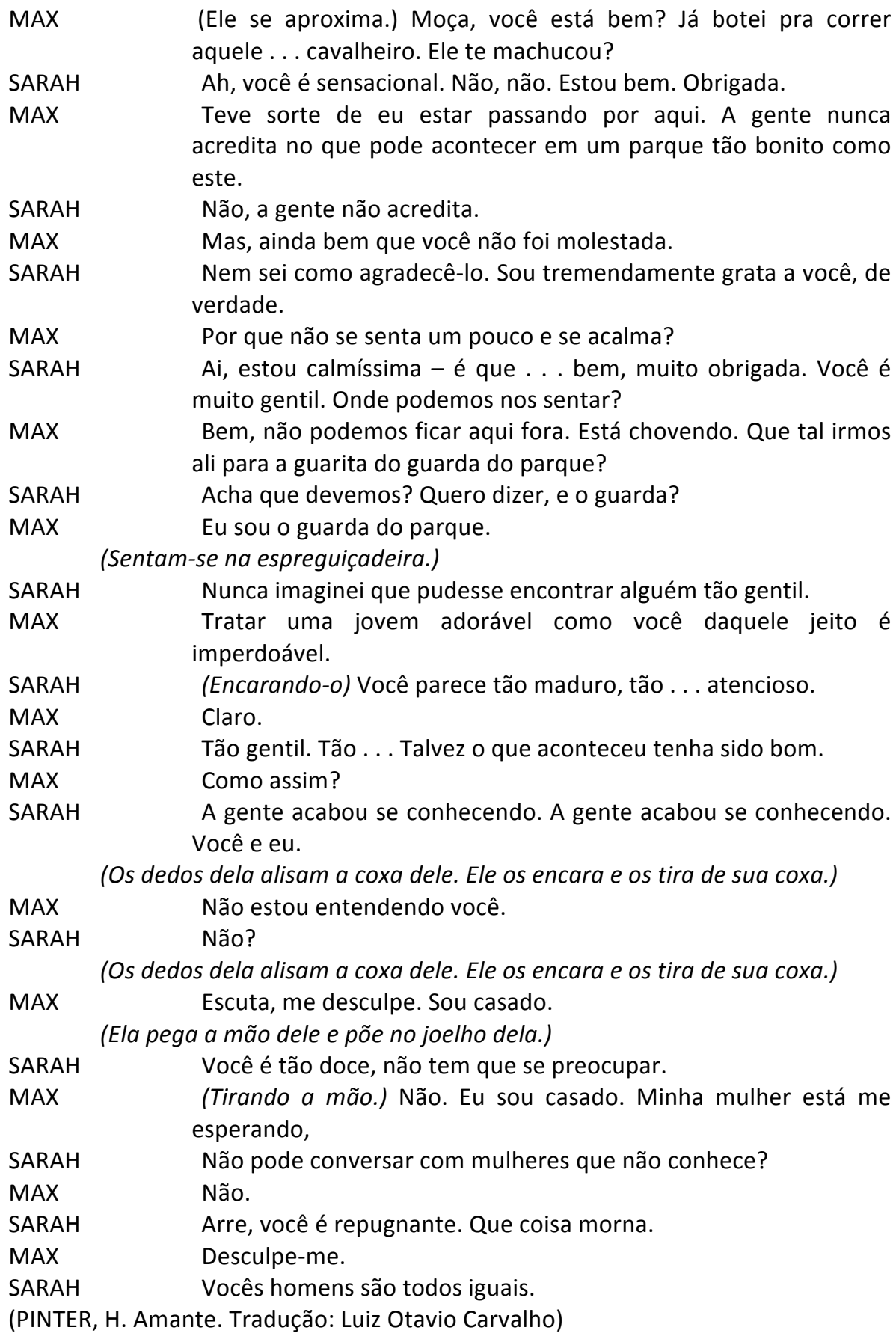

Começa, então, outro jogo. Um jogo fantasioso entre eles, onde Sarah e Max passam a ser outros personagens da fantasia que eles mesmos criaram para o jogo erótico. Os personagens se transformam, pois, seus alvos e as circunstâncias propostas do texto se modificam. Esse jogo faz parte do erotismo que a cena propõe e os personagens vivenciam. Max agora é o guarda do 
parque e Sarah uma donzela em perigo. Neste momento, inicia o atacar de Sarah, a donzela. Ao sentar um ao lado do outro, inicia uma paquera, onde Sarah faz suas investidas e Max foge, ao mesmo tempo em que também paquera Sarah. Os alvos de ambos são um e o outro. Max disfarça e foge das investidas de Sarah. Ele dissimuladamente apresenta a suposta esposa como um problema para a paquera entre os dois.

Por meio desses exemplos, fica evidente, para mim, que a dramaturgia de Pinter muito antes de pretender contar uma história, apresenta, de fato, situações. Nesse tipo de contexto, a construção do papel não se beneficia por meio de perguntas tradicionais, como 'Quem sou eu?' e 'O que devo sentir?'. Para isso, as reflexões de Donnellan me auxiliaram bastante para que eu conseguisse reagir e desenvolver uma atuação viva e presente. Além disso, a cada vez que repito as cenas, minha atenção é convocada a ficar bem ligada, porque tenho que reagir às proposições e não contar com fatores emocionais ou vivenciais previamente determinados.

\section{CONSIDERAÇÕES FINAIS}

Um teatro vivo em que o ator consegue expressar relações de forma verdadeira e crível, se torna muito mais motivador para o espectador, fazendo com que este pense, envolva-se na trama, instigando-o a estar ali atento.

O ator é um elemento cênico potente e importante. Está sempre buscando uma atuação que afete o espectador de alguma maneira expressiva, por meio do trabalho vocal e corporal. Para isso, torna-se extremamente relevante o treino de sua imaginação e o estudo de poéticas de atuação. Trabalhar com o teatro do absurdo de Harold Pinter foi para mim inusitado, mas ao mesmo tempo surpreendente, pois pude perceber cotidianos imersos em uma espera de situações para além do comum.

Atuar é, no meu ponto de vista, muito mais trabalho do que talento. Quando digo trabalho me refiro ao estudo, empenho e à vontade de fazer. Ao eleger uma peça de Harold Pinter para fazer parte do meu exercício cênico de TCC, escolho também um teatro de possibilidades de aprofundamento de atuação, pois, conheci outra linguagem teatral da qual eu não tinha experiência e vivência. A construção de um papel sempre foi algo que me chamou muito a atenção, pois ao meu ver, é a essência do fazer teatral. Construir Sarah foi um desafio instigante, 
indo na contramão de tudo que já havia experimentado na minha vida de atriz e estudante de teatro.

Outra realização satisfatória que pude experimentar nesse término do meu Curso de Graduação foi perceber como a teoria de desbloqueio de atuação cênica de Declan Donnellan pôde me ajudar significativamente na construção do papel de Sarah em consonância com a linguagem dramatúrgica de Pinter. Ao entender a personagem de Pinter e as reflexões de Donellan sobre o jogo cênico, percebi de imediato o quanto esses dois raciocínios se integravam. Pude selar uma série de aprendizagens em relação à Teoria do Alvo ao construir Sarah, com reações imediatas e orgânicas. Trabalhar uma personagem pinteriana tendo como ferramenta o alvo me possibilitou uma criação mais viva, verdadeira e fluida, uma vez que vendo os alvos não finjo atuar e sim atuo de fato, a partir das provocações que este alvo me proporciona. Reagir ao que se vê é sempre mais potente do que inventar reações, pois quando vemos somos espontâneos, quando inventamos, temos que buscar na memória o que foi mecanizado e então apenas representamos e não atuamos.

\section{Referências}

DONNELLAN, Declan. $\mathbf{O}$ ator e o alvo. Tradução de Luiz Otavio Carvalho e Vinícius Albricker. São Paulo: Via Lettera, no prelo.

ESSLIN, Martin. O teatro do absurdo. Tradução de Bárbara Heliodora. Rio de Janeiro: Zahar Editores, 1961.

. Pinter: the playwright. London and New York: Methuen, 1984, Fourth Edition.

HAYMAN, Ronald. Contemporary playwrights: Harold Pinter. London: Heinemann, 1975, Third Edition.

PINTER, Harold. Amante. Tradução de Luiz Otavio Carvalho.

Artigo submetido em 31/07/2019, e aceito em 13/12/2019. 